\title{
KARAKTERISTIK MEKANIS CAMPURAN LASTON ATAS DENGAN PENAMBAHAN LIMBAH BUBUTAN BAJA
}

\author{
Nathanael $^{1}$ dan Anissa Noor Tajudin ${ }^{2}$ \\ ${ }^{1}$ Program Studi Sarjana Teknik Sipil, Universitas Tarumanagara, Jl. Letjen S. Parman No.1 Jakarta \\ Nathanae1.325160101@stu.untar.ac.id \\ ${ }^{2}$ Program Studi Sarjana Teknik Sipil, Universitas Tarumanagara, Jl. Letjen S. Parman No.1 Jakarta \\ anissat@ft.untar.ac.id
}

\begin{abstract}
The flexible pavement is burdened by a high volume of traffic vehicles leads to damage to the road. The innovation of the use of steel waste can also be one of the efforts to minimize the damage of the plight because steel waste is a good conductor and can help manage the surrounding waste to reduce the negative impact of waste on the community. Through this research, the mechanical characteristics of waste steel as added material will be tested for the type of asphalt concrete wearing course. Thus it will be known benefits of use of steel waste against asphalt mixture. . By using the waste of steel with the size of $\pm .0,5 \mathrm{~cm}$ and with a variation of $0,25 \%, 0,5 \%, 0,75 \%$, and $1 \%$ and the optimum asphalt rate obtained from previous research at 5,7\%. Once obtained characteristic data Marshall mixture, the research continue to determine the optimum material level with a narrow range method and performed mechanistic analysis of empirical using KENPAVE. , Then the results of the test can be seen in the characteristic Marshall, which is where these values are based on the general specifications of the Directorate General of Bina Marga Edition 2018.
\end{abstract}

Keywords: Flexible pavement; Steel Waste; Marshall

\begin{abstract}
ABSTRAK
Perkerasan lentur yang terbebani oleh volume lalu lintas yang tinggi dan menyebabkan terjadinya kerusakan pada jalan. Salah satu inovasi yang dapat digunakan untuk meminimalisir kerusakan lapis perkerasan dengan menggunakan limbah bubutan baja sebagai bahan tambah. Limbah bubutan baja merupakan konduktor yang baik, penggunaan bubutan baja ini juga dapat menjadi salah satu upaya untuk mengelola limbah yang ada di sekitar agar mengurangi dampak negatif limbah terhadap masyarakat. Melalui penelitian ini, karakteristik mekanis limbah bubutan baja sebagai bahan tambah akan diuji untuk jenis campuran asphalt concrete wearing course (AC - WC). dengan demikian akan diketahui manfaat penggunaan limbah bubutan baja terhadap campuran aspal. Dengan menggunakan limbah bubutan baja yang sudah dipotong hingga ukuran $\pm .0,5 \mathrm{~cm}$ dan dengan kadar variasi sebesar 0,25\%, 0,5\%, 0,75\%, dan 1\% serta kadar aspal optimum yang didapat dari penelitian sebelumnya, yaitu sebesar 5,7\%. Setelah didapatkan data karakteristik Marshall campuran, penelitian dilanjutkan untuk menentukan kadar bahan optimum dengan metode narrow range dan dilakukan analisis mekanistik empiris menggunakan KENPAVE. Kemudian hasil pengujian tersebut dapat dilihat pada karakteristik Marshall, yang dimana nilai-nilai tersebut berdasarkan Spesifikasi Umum Direktorat Jendral Bina Marga Edisi 2018.
\end{abstract}

Kata kunci: Perkerasan Lentur; Limbah Bubutan Baja; Marshall

\section{PENDAHULUAN}

Jalan raya adalah jalur - jalur tanah di atas permukaan bumi yang dibuat oleh manusia dengan bentuk, ukuran dan jenis konstruksinya sehingga dapat digunakan untuk menyalurkan lalu lintas orang, hewan dan kendaraan yang mengangkut barang dari suatu tempat ke tempat lainnya dengan mudah dan cepat. (Clarkson H. Oglesby. 1999).

Jalan raya terbentuk dari beberapa lapisan yaitu Subgrade, Sub Base Course, Base Course dan Surface Course. Perkerasan jalan raya dibuat berlapis-lapis bertujuan untuk menerima beban kendaraan yang melaluinya dan meneruskan kelapisan dibawahnya.

Perkerasan merupakan struktur yang terdiri dari banyak lapisan yang dibuat untuk menambah daya dukung tanah agar dapat memikul repetisi beban lalu lintas sehingga tanah tidak mengalami deformasi yang berarti. Sedangkan 
defenisi dari perkerasan jalan adalah bagian dari jalur lalu-lintas yang merupakan penampang struktur dalam kedudukan yang paling sentral dalam suatu badan jalan. Lalu-lintas langsung terkonsetrasi pada bagian ini, sehingga dapat dikatakan merupakan urat nadi suatu konstruksi jalan (Saodang, 2005). Perkerasan lentur terdiri dari surface course, base course, dan subbase yang dibentuk dari subgrade yang campurannya sudah dipadatkan. Dalam beberapa kasus, lapisan subbase tidak digunakan, sedangkan dalam sejumlah kecil kasus kedua base dan subbase dihilangkan (Mamlouk, 2006).

Di Indonesia sebagian besar kontruksi jalan menggunakan laston (lapisan aspal beton) sebagai lapis permukaan pada perkerasan lentur. Laston adalah campuran agregat kasar, agregat halus, filler dan aspal sebagai pengikat. Ciri cari dari Laston adalah memiliki sedikit rongga dalam struktur agregatnya, saling mengunci satu dengan yang lainnya, oleh karena itu aspal beton memiliki sifat stabilitas tinggi dan relatif kaku. (Bina Marga Departemen Pekerjaan Umum 2018)

Pertumbuhan ekonomi menyebabkan permintaan terhadap infrastruktur jalan yang layak dan nyaman semakin meningkat. Perkerasan lentur yang terbebani oleh volume lalu lintas yang tinggi dan perumbuhan jumlah kendaraan yang tidak terkontrol menyebabkan terjadinya kerusakan pada jalan. Pemeliharaan lapis permukaan jalan pada saat ini umumnya dikerjakan dengan ketebalan yang cukup tinggi, hal ini menimbulkan berbagai persoalan baru. Selain membutuhkan anggaran yang besar, pemeliharaan lapis permukaan jalan dengan ketebalan yang tinggi juga berdampak pada berbagai aspek, baik dari segi lingkungan sekitar jalan dan penggunaan material yang cukup banyak. Oleh karena itu, inovasi metode perkerasan jalan dibutuhkan untuk meningkatkan kualitas dari perkerasan tersebut.

Berdasarkan latar belakang diatas, maka terdapat inovasi dengan menggunakan bahan tambah limbah bubutan baja. Selain karena bubutan baja merupakan konduktor yang baik, penggunaan bubutan baja ini juga dapat menjadi salah satu upaya untuk mengelola limbah yang ada di sekitar agar mengurangi dampak negatif limbah terhadap masyarakat di masa depan. Melalui penelitian ini, karakteristik mekanis limbah bubutan baja sebagai bahan tambah akan diuji untuk jenis campuran asphalt concrete wearing course (AC - WC). Oleh karena itu, penelitian ini perlu dilakukan untuk meneliti bagaimana limbah bubutan baja sebagai bahan tambah untuk campuran aspal.

Batasan Masalah pada penelitian ini:

1. Karakteristik campuran yang akan diuji dan dianalisis adalah stabilitas Marshall, Void in Mineral Agregat (VMA), Void in the Mix (VIM) dan Void Filled with Asphalt ((VFA) dan Cantabro Test.

2. Agregat yang digunakan berasal dari Cikarang Barat, Bekasi.

3. Jenis campuran yang digunakan adalah AC - WC.

4. Limbah bubutan baja sebagai bahan tambah digunakan sebanyak $0 \%, 0.25 \%, 0.5 \%, 0.75 \%$, dan $1 \%$ dari total berat campuran

5. Aspal yang digunakan adalah aspal pertamina dengan penetrasi $60 / 70$

6. Job mix design dan kadar aspal rencana menggunakan hasil penelitian terdahulu.

Berdasarkan masalah yang dirumuskan pada rumusan masalah, maka tujuan dari penulisan topik ini adalah:

1. Menganalisis nilai pengaruh $0 \%, 0,25 \%, 0,5 \%, 0,75 \%$, dan $1 \%$ limbah bubutan baja terhadap campuran aspal pada parameter Marshall

2. Menganalisis nilai pengaruh $0 \%, 0,25 \%, 0,5 \%, 0,75 \%$, dan $1 \%$ limbah bubutan baja terhadap campuran aspal pada karakteristik volumetric.

Berdasarkan penelitian terdahulu, dilakukan penelitian menggunakan penambahan bubutan:

1. Adhe Pramudya melakukan penelitian untuk mengetahui pengaruh penambahan limbah bubutan baja pada lapis tipis campuran aspal panas terhadap karakteristik kuat tarik tidak langsung, kuat tekan bebas dan permeabilitas

2. Alpha Tora melakukan penelitian untuk pengaruh penambahan limbah bubutan baja pada lapis tipis campuran aspal panas terhadap karakteristik Marshall

\section{METODE PENELITIAN}

\section{Alur penelitian}

Dalam melakukan penelitian ini dimulai dengan mengumpulkan data - data terlebih dahulu baik data bahan maupun data yang terkait dengan tipe Asphalt Concrete - Wearing Course (AC - WC) dengan panduan Binamarga. Penelitian in dilakukan di laboratorium Perkerasan Jalan Raya, Universitas Tarumanagara dan kemudian dilanjutkan oleh PT. Marga Maju Mapan. Berikut merupakan diagram tahapan alir penelitian (flowchart) yang ditunjukkan dalam Gambar 1. 


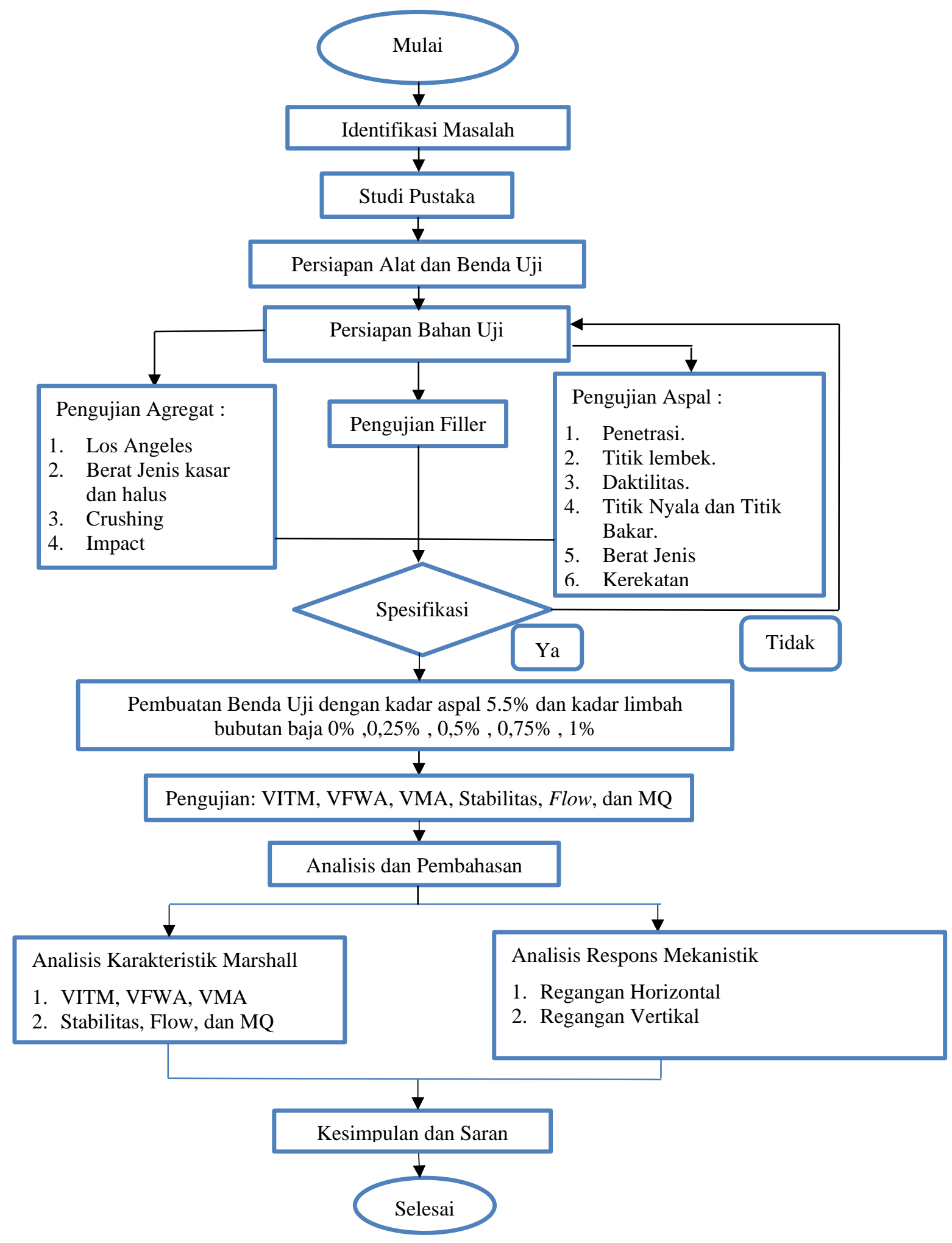

Gambar 1. Diagram alir penelitian 


\section{Pemeriksaan bahan}

Pada tahapan ini pekerjaan yang akan dilaukan adalah pemeriksaan bahan yang akan digunakan dalam penelitian ini, meliputi:

A. Pemeriksaan Agregat

1. Analisa saringan agregat kasar dan agregat halus yang bertujuan untuk memisahkan gradasi antar ukuran agregat yang berbeda.

2. Pemeriksaan keausan agregat menggunakan mesin abrasi Los Angeles yang bertujuan untuk mengetahui ketahanan agregat kasar terhadap keausan dengan menggunakan mesin abrasi Los Angeles berdasarkan SNI 2417:2008. Nilai yang tinggi menunjukkan hancurnya bagian benda uji yang terjadi akibat tumbukkan dengan bola baja yang berada di dalam mesin Los Angeles.

3. Pemeriksaan berat jenis dan penyerapan agregat kasar yang bertujuan untuk menentukan berat jenis curah (bulk), berat kering permukaan jenuh (saturated surface dry $=S S D$ ), dan berat jenis semu (apparent) dari agregat kasar.

4. Pemeriksaan berat jenis dan penyerapan agregat halus yang bertujuan untuk menentukan berat jenis curah (bulk), berat kering permukaan jenuh (saturated surface dry $=S S D$ ), dan berat jenis semu (apparent) dari agregat halus.

5. Pemeriksaan berat jenis filler yang bertujuan untuk menentukan berat jenis curah (bulk) dari filler.

6. Pemeriksaan penyelimutan dan pengelupasan agregat terhadap aspal bertujuan untuk menentukan kelekatan agregat terhadap aspal di dalam SNI 2439:2011. Nilai yang diambil adalah persentase luas permukaan agregat yang terselimuti aspal terhadap seluruh luas agregat.

B. Pemeriksaan Aspal

Aspal merupakan hasil olahan alam yang perlu dilakukan pemeriksaan agar dapat memenuhi karakteristik yang mendukung kualitas suatu perkerasan jalan. Selain itu, aspal perlu diuji kembali agar memenuhi syarat syarat yang telah ditetapkan. Adapun pemeriksaan aspal tersebut meliputi:

1. Pemeriksaan penetrasi aspal

Pengujian Penetrasi dimaksudkan untuk mengukur konsistensi aspal, nilai penetrasi yang tinggi menunjukkan konsistensi aspal yang lebih lunak. pengujian ini dapat digunakan untuk pengendalian mutu aspal atau tar untuk keperluan pembangunan, peningkatan, dan pemeliharaan jalan. (SNI 2456:2011)

2. Pemeriksaan daktilitas

Pemeriksaan ini ditujukan untuk mengetahui sifat kohesi dari aspal tersebut dengan cara mengukur jarak terpanjang aspal yang ditarik hingga aspal putus pada suhu dan kecepatan yang telah ditentukan.

3. Pemeriksaan titik lembek aspal

Pada umumnya cara pemeriksaan ini menggunakan cincin kuningan dan menuangkan aspal secara merata lalu diletakkan bola baja diatasnya dan dipanaskan secara bersamaan. Titik lembeknya adalah suhu pada saat bola baja dengan berat tertentu mendesak turun suatu lapisan aspal atau tar yang tertahan dalam cincin ukuran tertentu, sehingga aspal akan menyentuh plat dasar yang terletak dibawah cincin pada tinggi tersebut akibat pemanasan pada aspal tersebut.

4. Pemeriksaan titik nyala dan titik bakar

Pemeriksaan ini ditujukan untuk mengukur kecenderungan aspal dapat terbakar akibat panas dan api pada kondisi terkontrol di laboratorium.

5. Pemeriksaan berat jenis aspal

Pemeriksaan ini dimaksudkan untuk mengetahui berat jenis aspal dengan menggunakan piknometer. Berat jenis aspal adalah perbandingan berat volume aspal dengan berat volume air.

\section{Perancangan benda uji}

A. Perancangan Benda Uji

Rancangan gradasi dan komposisi agregat campuran control disajikan dalam Tabel 1 dan grafik gradasi agregat dalam Gambar 2 berikut. 
Tabel 1. Rancangan gradasi dan komposisi agregat untuk campuran

\begin{tabular}{|c|c|c|c|c|c|c|c|c|}
\hline \multirow{2}{*}{ Bahan } & \multicolumn{2}{|c|}{ Saringan } & \multicolumn{3}{|c|}{$\begin{array}{c}\text { Spesifikasi Lolos } \\
\text { (\%) }\end{array}$} & \multirow{2}{*}{$\begin{array}{c}\text { Tinggal } \\
\text { Di Atas } \\
\text { (\%) }\end{array}$} & \multicolumn{2}{|c|}{$\begin{array}{c}\text { Jumlah Menurut } \\
\text { Spesifikasi }\end{array}$} \\
\hline & $\mathrm{mm}$ & \# & Min & Max & Target & & $\begin{array}{l}\text { Tinggal } \\
(\%)\end{array}$ & (gram) \\
\hline \multirow{2}{*}{$\begin{array}{l}\text { Agregat } \\
\text { Kasar }\end{array}$} & 19,1 & $3 / 4 "$ & 100 & 100 & 100 & 0 & 0 & 0 \\
\hline & 12,7 & $1 / 2 "$ & 90 & 100 & 96,5 & 3,5 & 3,5 & 42 \\
\hline \multirow{2}{*}{$(42,22 \%)$} & 9,52 & 3/8” & 77 & 90 & 83,8 & 16,2 & 12,7 & 153 \\
\hline & 4,76 & $\# 4$ & 53 & 69 & 57,8 & 42,2 & 26 & 312 \\
\hline \multirow{3}{*}{$\begin{array}{c}\text { Agregat } \\
\text { Halus }\end{array}$} & 2,36 & $\# 8$ & 33 & 53 & 38,9 & 61,2 & 18,9 & 227 \\
\hline & 1,18 & \#16 & 21 & 40 & 25,9 & 74,1 & 13 & 156 \\
\hline & 0,59 & \#30 & 14 & 30 & 19,9 & 80,2 & 6 & 72 \\
\hline \multirow{3}{*}{$(51,67 \%)$} & 0,279 & $\# 50$ & 9 & 22 & 14,6 & 85,5 & 5,3 & 64 \\
\hline & 0,149 & $\# 100$ & 6 & 15 & 9,9 & 90,1 & 4,7 & 56 \\
\hline & 0,074 & \#200 & 4 & 10 & 6,1 & 93,9 & 3,8 & 45 \\
\hline $\begin{array}{c}\text { Filler } \\
(6,11 \%)\end{array}$ & PAN & & & & & 100 & 6,1 & 73 \\
\hline
\end{tabular}

(Sumber: Esmeralda dan Pangestu, 2019)

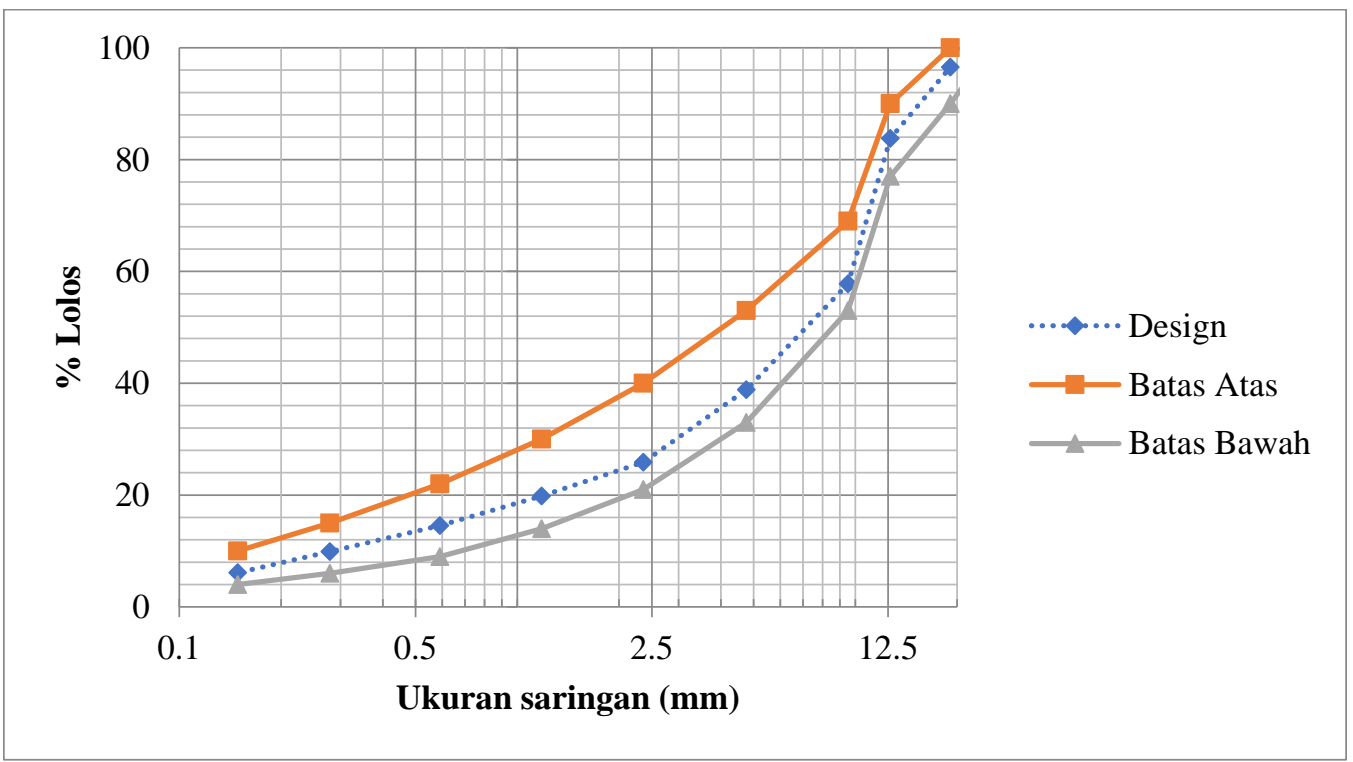

Gambar 2. Gradasi agregat rencana

Kadar aspal optimum sebesar 5.5\%
A. Variasi Bubutan Baja Yang Digunakan
Variasi kadar Bubutan Baja yang digunakan dalam penelitian ini sebesar 0\%, 0,25\%; 0,5\%; 0.75\% ;1\% dari berat total agregat.
B. Jumlah Benda Uji
Jumlah benda uji yang ditetapkan dalam penelitian ini akan disajikan dalam Tabel 2. 
Tabel 2. Rancangan jumlah benda uji

\begin{tabular}{ccc}
\hline No. & Jenis Benda Uji & Jumlah \\
\hline 1. & Benda uji perendaman standard dengan variasi limbah & $3 \times 5=15$ BU \\
2. & bubutan baja 0\%; 0,25\%; 0,5\%; 0,75\%; 1\% & $3 \times 5=15$ BU \\
3. & Pengujian Cantabro & $3 \times 5=15$ BU \\
\hline & Pengujian Marhall perendaman 24 jam & 45 BU \\
\hline
\end{tabular}

\section{HASIL DAN PEMBAHASAN}

\section{Pembahasan penelitian}

Penggunaan agregat pada penelitian ini berasal dari Cibarusa, Bekasi, Jawa Barat. Aspal yang digunakan dalam penelitian ini menggunakan aspal dari pertamina dengan penetrasi 60/70. Agregat dan aspal diuji sifat fisiknya di Laboratorium Jalan Raya dan Transportasi Universitas Tarumanagara dengan syarat yang telah ditetapkan pada Spesifikasi Umum Direktorat Jenderal Bina Marga Edisi 2018). Kemudian penelitian ini menguji penambahan limbah bubutan baja dengan variasi kadar tertentu terhadap karaktersitik Marshall campuran beraspal.

\section{Hasil pemeriksaan fisik agregat}

Agregat kasar, agregat halus, serta filler yang digunakan untuk campuran (AC-WC) berasal dari Cibarusa, Bekasi, Jawa Barat. Hasil pemeriksaan fisik agregat meliputi agregat kasar, agregat halus, dan filler disajikan pada Tabel 3.

Tabel 3. Hasil pemeriksaan fisik agregat

\begin{tabular}{llllll}
\hline No & Jenis Pengujian & Syarat & Hasil & Satuan & Keterangan \\
\hline A. Agregat Kasar & & & & \\
\hline 1 & Abrasi dengan mesin Los Angeles & Maks 40 & 32,962 & $\%$ & Memenuhi \\
2 & Kelekatan Terhadap Aspal & Min 95 & 98 & $\%$ & Memenuhi \\
3 & Berat Jenis Semu & Min 2,5 & 2,69 & $\mathrm{~g} / \mathrm{cm}^{3}$ & Memenuhi \\
4 & Absorpsi & Maks 3 & 0,55 & $\%$ & Memenuhi \\
\hline B. Agregat Halus & & & & \\
\hline 1 & Absorpsi & Maks 3 & 2,88 & $\%$ & Memenuhi \\
2 & Berat Jenis Semu & Min 2,5 & 2,72 & $\mathrm{~g} / \mathrm{cm}^{3}$ & Memenuhi \\
\hline C. Filler & & & & \\
\hline 1 & Berat Jenis Semu & Min 2,5 & 2,5 & $\mathrm{~g} / \mathrm{cm}^{3}$ & Memenuhi \\
\hline
\end{tabular}

Sesuai dengan hasil dari pengujian pada Tabel 3 yang dilakukan maka material agregat kasar, halus, dan filler dapat digunakan sebagai bahan campuran agregat pada AC-WC karena memenuhi semua syarat.

\section{Hasil pemeriksaan sifat fisik aspal}

Hasil pemeriksaan sifat fisik aspal dilakukan dengan material aspal Pertamina Pen 60/70 yang disajikan pada Tabel 4.

Tabel 4. Hasil pemeriksaan fisik aspal

\begin{tabular}{cccc}
\hline No. & Jenis Pengujian & Spesifikasi & Hasil \\
\hline 1 & Penetrasi pada $25^{\circ} \mathrm{C}(\mathrm{dmm})$ & $60-70$ & 68 \\
2 & Titik Lembek $(\mathrm{C})$ & $\geq 48$ & 52 \\
3 & Daktilitas pada $25^{\circ} \mathrm{C}(\mathrm{cm})$ & $\geq 100$ & 111,2 \\
4 & Titik Nyala (C) & $\geq 232$ & 323 \\
5 & Berat Jenis (gr/cc) & $\geq 1,0$ & 1,036 \\
\hline
\end{tabular}

Berdasarkan dengan hasil dari pengujian pada Tabel 4 yang dilakukan untuk bahan aspal sudah memenuhi persyaratan yang telah ditetapkan dan dapat digunakan sebagai bahan campuran aspal pada AC-WC. 


\section{Analisis perkiraan kadar aspal optimum}

Penentuan perkiraan kadar aspal optimum adalah langkah perhitungan yang akan dilakukan untuk menentukan kadar aspal pada suatu perancangan campuran perkerasan berdasarkan dengan data hasil penelitian terdahulu, yaitu sebesar 5,7\%

\section{Hasil pengujian Marshall}

Hasil uji Marshall dengan penggunaan agregat pada berbagai kadar bubutan baja dipresentasikan pada Tabel 5, Tabel 6, Tabel 7, dan Tabel 8 berikut.

Tabel 5. Hasil pengujian Marshall dengan variasi bubutan baja 0,25 \%

\begin{tabular}{ccc}
\hline Kriteria & Spesifikasi & Hasil \\
\hline VFWA & $>65 \%$ & 79,00 \\
VITM & $3-5 \%$ & 3,37 \\
VMA & $>15 \%$ & 16,07 \\
Stabilitas & $>800 \mathrm{~kg}$ & 1390 \\
Flow & $>3 \mathrm{~mm}$ & 3,90 \\
MQ & $>250 \mathrm{~kg} / \mathrm{mm}$ & 348
\end{tabular}

Tabel 6. Hasil pengujian Marshall dengan variasi bubutan baja 0,5 \%

\begin{tabular}{ccc}
\hline Kriteria & Spesifikasi & Hasil \\
\hline VFWA & $>65 \%$ & 79,99 \\
VITM & $3-5 \%$ & 3,18 \\
VMA & $>15 \%$ & 15,90 \\
Stabilitas & $>800 \mathrm{~kg}$ & 1456 \\
Flow & $>3 \mathrm{~mm}$ & 3,93 \\
MQ & $>250 \mathrm{~kg} / \mathrm{mm}$ & 370 \\
\hline
\end{tabular}

Tabel 7. Hasil pengujian Marshall dengan variasi bubutan baja 0,75 \%

\begin{tabular}{ccc}
\hline Kriteria & Spesifikasi & Hasil \\
\hline VFWA & $>65 \%$ & 80,67 \\
VITM & $3-5 \%$ & 3,06 \\
VMA & $>15 \%$ & 15,79 \\
Stabilitas & $>800 \mathrm{~kg}$ & 1468 \\
Flow & $>3 \mathrm{~mm}$ & 4,05 \\
MQ & $>250 \mathrm{~kg} / \mathrm{mm}$ & 365 \\
\hline
\end{tabular}


Tabel 8. Hasil pengujian Marshall dengan variasi bubutan baja $1 \%$

\begin{tabular}{ccc}
\hline Kriteria & Spesifikasi & Hasil \\
\hline VFWA & $>65 \%$ & 81,27 \\
VITM & $3-5 \%$ & 2,94 \\
VMA & $>15 \%$ & 15,69 \\
Stabilitas & $>800 \mathrm{~kg}$ & 1500 \\
Flow & $>3 \mathrm{~mm}$ & 4,05 \\
MQ & $>250 \mathrm{~kg} / \mathrm{mm}$ & 370
\end{tabular}

Pengujian dilakukan dengan alat uji Marshall dan data yang dipakai adalah VITM, VFWA, VMA, Stabilitas, Flow, dan MQ. Serta dengan batasan yang telah ditentukan oleh spesifikasi Direktorat Jenderal Bina Marga Edisi 2010 (revisi 1). Tabel 4.3, 4.4, 4.5 dan 4.6 merupakan dari perhitungan dan pembacaan dari alat uji Marshall yang dilakukan oleh peneliti.

Pada Tabel 5 merupakan hasil penggunaan bubutan baja dengan kadar 0,25\% dari berat campuran AC-WC. Dilihat dari data Tabel 5 nilai VITM, VFWA, VMA, Stabilitas, Flow, dan MQ sudah memenuhi spesifikasi.

Pada Tabel 6 merupakan hasil penggunaan bubutan baja dengan kadar 0,5\% dari berat campuran AC-WC. Dilihat dari data Tabel 6 nilai VITM, VFWA, VMA, Stabilitas, Flow, dan MQ sudah memenuhi spesifikasi.

Pada Tabel 7 merupakan hasil penggunaan bubutan baja dengan kadar 0,75\% dari berat campuran AC-WC. Dilihat dari data Tabel 7 nilai VITM, VFWA, VMA, Stabilitas, Flow, dan MQ sudah memenuhi spesifikasi

Pada Tabel 8 merupakan hasil penggunaan bubutan baja dengan kadar 1\% dari berat campuran AC-WC. Dilihat dari data Tabel 8 nilai VFWA, VMA, Stabilitas, Flow, dan MQ sudah memenuhi spesifikasi. Namun VITM pada kadar $1 \%$ berada dibawah batas minimum dan untuk kadar lainnya berada pada batas spesifikasi. Sedangkan untuk nilai VMA, VFWA, Stabilitas, Flow, dan MQ telah memenuhi syarat.

\section{Analisis pengaruh penambahan limbah bubutan baja terhadap karakteristik Marshall}

Setelah melakukan pengujian, perhitungan, dan Analisis terhadap karakteristik dan sifat fisik dari aspal dan agregat serta campuran, maka padatahap ini akan dibahas mengenai pengertian dari karakterisitik Marshall dan ditampilkan data-data hasil pengujian tersebut dalam bentuk grafik, yang dapat dilihat pada Gambar 3 hingga Gambar 8 berikut.

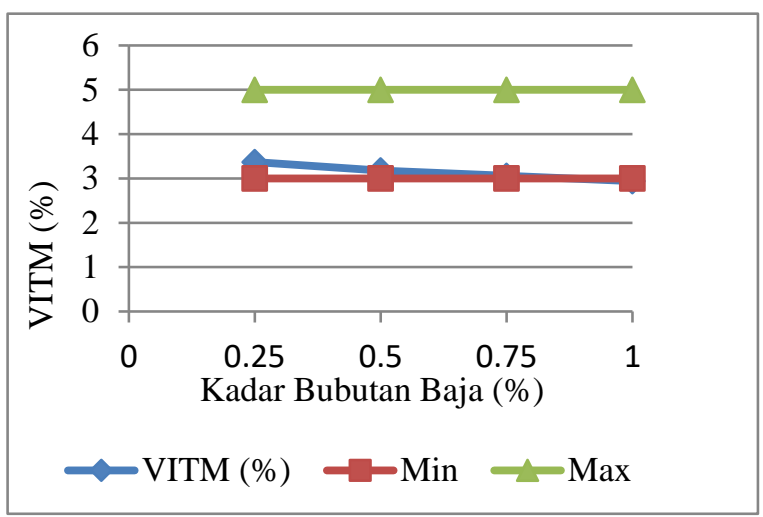

Gambar 3. Hubungan kadar bubutan baja dan VITM

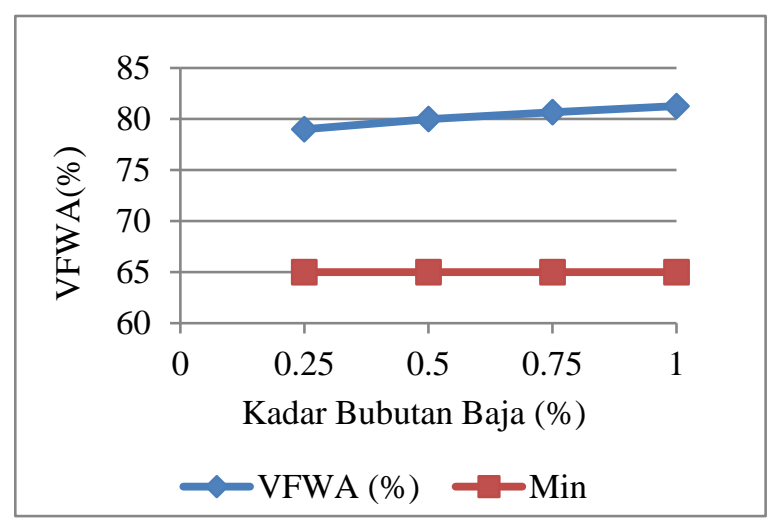

Gambar 4. Hubungan kadar bubutan baja dan VFWA 


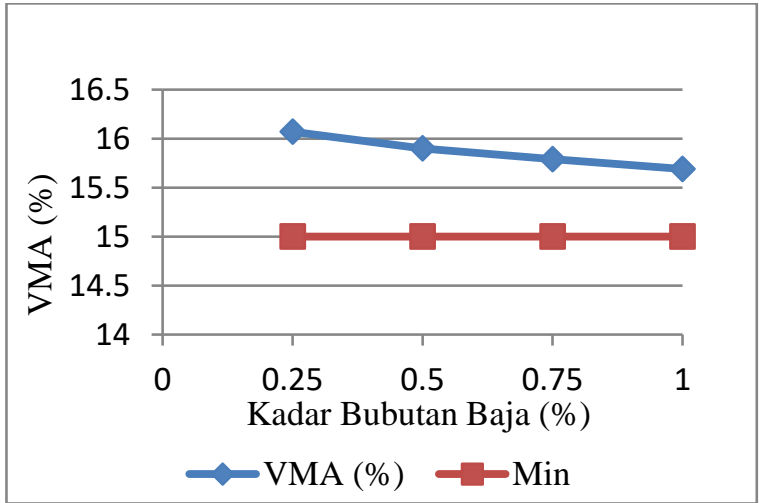

Gambar 5. Hubungan kadar bubutan baja dengan nilai VMA

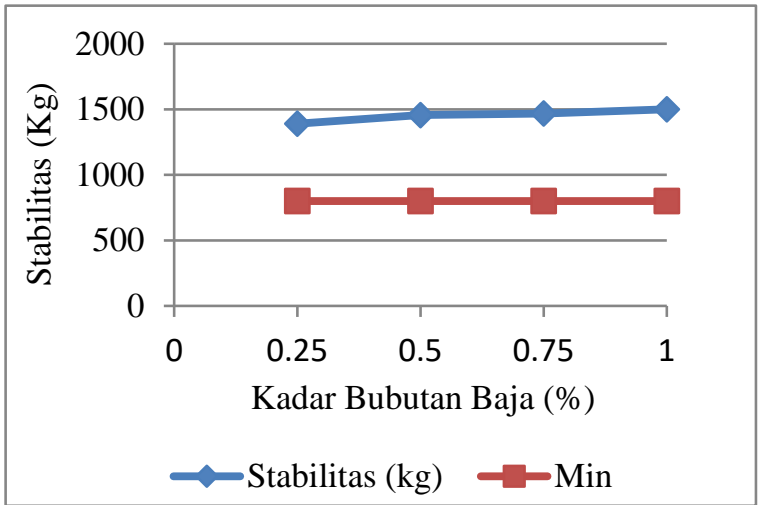

Gambar 6. Hubungan kadar bubutan baja dengan nilai stabilitas

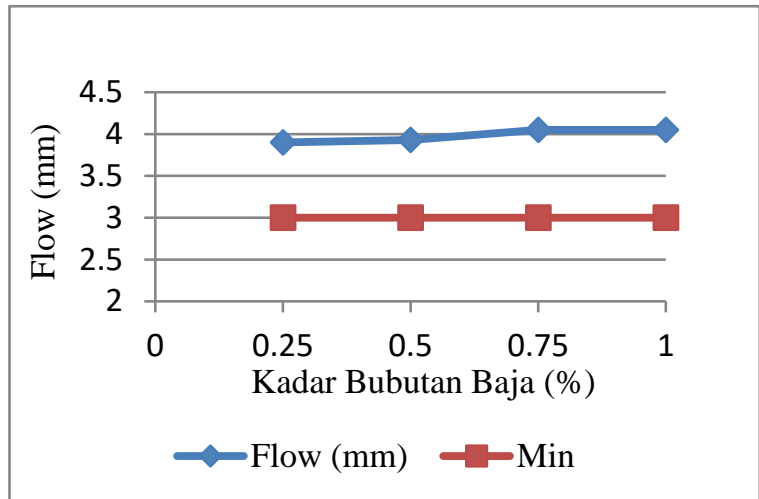

Gambar 7. Hubungan kadar bubutan baja dengan nilai flow

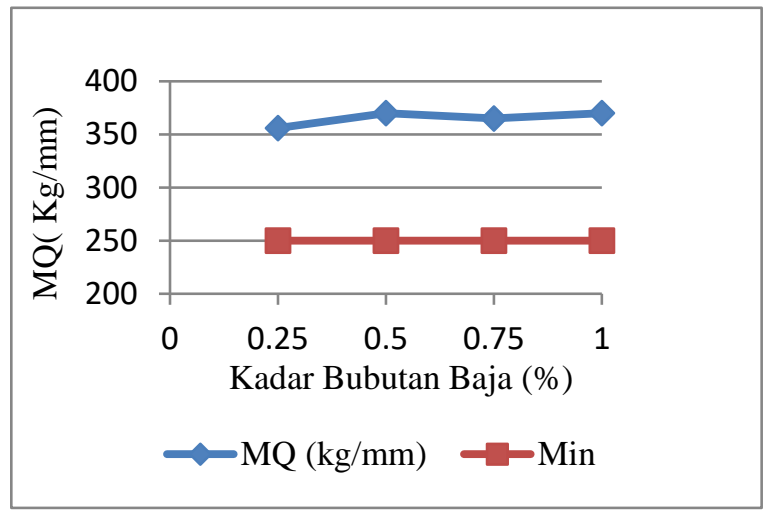

Gambar 8. Hubungan kadar bubutan baja dengan nilai MQ 


\section{Nilai VFWA (void filled with asphalt)}

Nilai VFWA yang didapat pada semua kadar buubutan baja berada di atas batas minimum dari VFWA. Hal ini disebabkan tingginya kadar aspal yang digunakan maka semakin tinggi nilai VFWA karena aspal akan mengisi rongga pada campuran. Juga dapat dilihat bahwa pada kadar aspal 5,7\% penambahan bubutan baja akan meningkatkan nilai VFWA. Nilai VFWA yang didapat pada grafik tersebut berada d atas batas minimum dan memenuhi syarat spsifikasi. Hal ini dikarenakan bubutan baja yang tidak memliki rongga udara sehingga aspal dapat mengisi agregat dan melapisi agregat dengan cepat. Bubutan baja tidak akan menjadi lunak saat dipanaskan, maka aspal tidak akan merekatkan butiran bubutan baja yang satu dengan bubutan baja yang lainnya, sehingga tidak terjadi penggumpalan yang dapat menghalang aspal untuk mengisi rongga pada campuran AC-WC.

\section{Nilai VITM (void in the mix)}

Pada kadar aspal 5,7\% menunjukkan bahwa penambahan bubutan baja menurunkan nilai VITM dan masih berada diatas batas minimum, namun pada penambahan kadar bubutan baja 1\%, nilai VITM berada di bawah nilai minimum. Hal ini dikarenakan gradasi agregat dalam campuran AC - WC yang digunakan dalam penelitian ini merupakan gradasi padat. Kadar aspal yang digunakan dalam penelitian ini pun relatif tinggi sehingga menyebabkan terjadi nya penurunan nilai VITM seiring dengan penambahannya bubutan baja. dan campuran dengan bubutan baja 1\%. Nilai VITM pada penambahan bubutan baja 1\% berada sedikit di bawah batas minimum yang menunjukkan bahwa dengan nilai kadar aspal yang lebih rendah, terdapat kemungkinan bahwa nilai VITM pada penambahan bubutan baja $1 \%$ berada di atas batas minimum.

\section{Nilai VMA (void mineral aggregate)}

Terlihat bahwa penambahan kadar bubutan baja pada campuran dengan kadar aspal 5,7\% akan menurunkan nilai VMA dan berada di atas syarat minimum dari spesifikasi yang ada. Hal ini dikarenakan penambahan bubutan baja mengakibatkan penurunan rongga yang akan diisi oleh aspal sehingga menurunkan nilai VMA. Karena jumlah kadar aspal yang cukup tinggi, maka nilai VMA semakin menurun sementara nilai VFWA semakin meningkat. Penurunan VMA juga dikarenakan campuran yang lebih padat dan gradasi rapat yang dihasilkan oleh penambahan bubutan baja.

\section{Nilai stabilitas Marshall}

Dari Gambar, tampak bahwa penambahan bubutan baja pada campuran akan meningkatkan nilai stabilitas dari campuran AC- WC. Hal ini disebabkan karena kadar aspal yang berfungsi sebagai perekat. Dari grafik tersebut menunjukkan bahwa semakin bertambah kadar bubutan baja dalam campuran, maka nilai stabilitas semaking meningkat dan berada di atas syarat batas minmum. Peningkatan nilai stabilitas disebabkan oleh bubutan baja yang dapat meningkatkan kualitas interlocking antar agregat dan pelapisan aspal pada agregat.

\section{Nilai flow Marshall}

Pada Gambar dapat dilihat bahwa penambahan kadar bubutan baja akan menyebabkan nilai flow cenderung meningkat. Hal ini terjadi karena semakin tinggi kadar bubutan baja, maka campuran akan menjadi semakin lunak, sehingga nilai aspal meningkat saat dibebani.

\section{Nilai Marshall quotient}

Dari Gambar 8, tampak bahwa penambahan bubutan baja pada campuran akan cenderung meningkatkan nilai Marshall quotient dari campuran. Dapat dilihat dari grafik bahwa nilai MQ berada diatas syarat batas minimum, mengingat nilai stabilitas campuran yang cukup tinggi.

\section{Penentuan kadar bahan optimum dengan narrow range}

Metode narrow range digunakan dengan cara penentuan nilai tengah dari nilai maksimum dan minimum dari semua kondisi. Dalam menentukan KAO kondisi yang dimaksud adalah nilai density, VFWA, VITM, VMA, stabilitas 5 flow. Pada Gambar 9 menunjukkan wilayah karakteristik yang memenuhi spesifikasi Bina Marga sehingga KAO dapat ditentukan. 


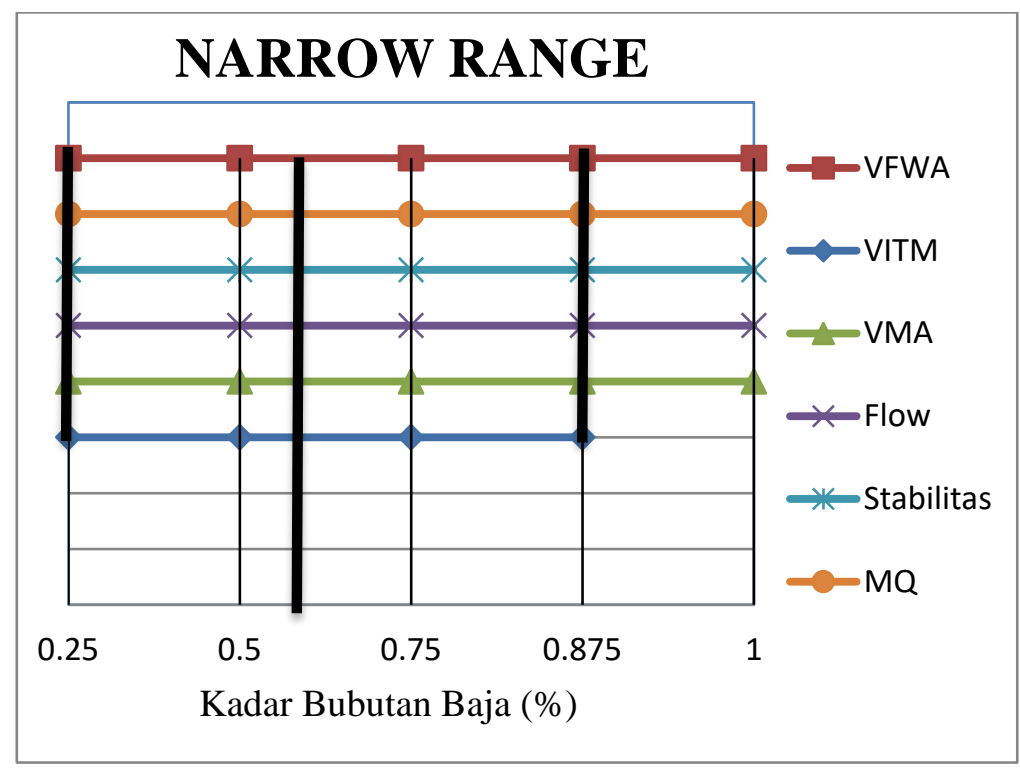

Gambar 9 Narrow Range kadar bahan optimum

Kadar bahan optimum diambil dengan metode Narrow Range pada nilai tengah kadar bubutan baja yang memenuhi syarat dan dilakukan pembulatan keatas, yaitu sebesar 0,5625\%

\section{Modulus elastisitas}

Nilai modulus elastisitas didapat berdasarkan nilai stabilitas yang diuji dari laboratorium dan kemudian dikorelasi menggunakan grafik korelasi stabilitas Marshall dengan modulus, Grafik korelasi yang digunakan untuk mendapatkan nilai modulus seperti pada Gambar 10.

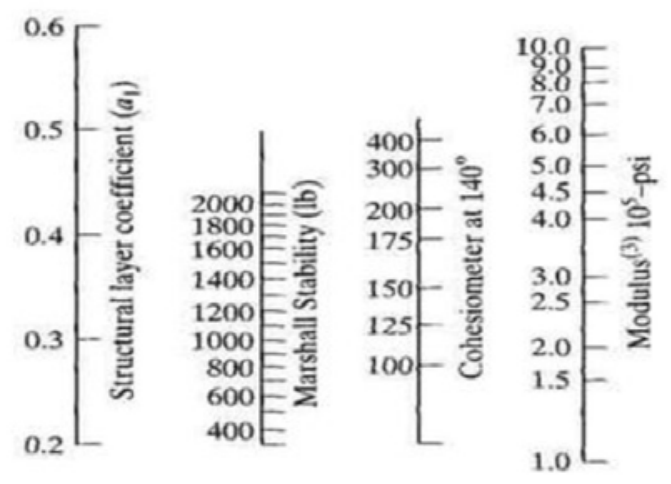

Gambar 10. Grafik korelasi stabilitas Marshall dan modulus (After Van Til dkk, 1972)

Setelah itu, data stabilitas dari hasil penelitian marshal dikonversikan menjadi modulus menggunakan grafik korelasi pada Gambar 10 yang hasilnya dapat dilihat pada Tabel 9.

Tabel 3.7 Nilai modulus

\begin{tabular}{cccccc}
\hline $\begin{array}{c}\text { Kadar } \\
\text { Bubutan } \\
\text { baja (\%) }\end{array}$ & $\begin{array}{c}\text { Stabilitas } \\
(\mathrm{kg})\end{array}$ & $\begin{array}{c}\text { Stabiitas } \\
(\mathrm{lb})\end{array}$ & $\begin{array}{c}\text { Modulus } \\
(\mathrm{psi})\end{array}$ & $\begin{array}{c}\text { Modulus } \\
(\mathrm{MPa})\end{array}$ & $\begin{array}{c}\text { Modulus } \\
(\mathrm{KPa})\end{array}$ \\
\hline 0.25 & 1390 & 3064,95 & 634460 & 4375,586 & 4375586 \\
0.5 & 1456 & 3210,48 & 663566 & 4576,317 & 4576317 \\
0.75 & 1468 & 3236,94 & 668858 & 4612,814 & 4612814 \\
1 & 1500 & 3307,5 & 682970 & 4710,138 & 4710138 \\
\hline
\end{tabular}




\section{Analisis Respon Mekanistik}

Output dari analisis menggunakan KENLAYER adalah nilai tegangan dan regangan yang terjadi pada perkerasan lentur jalan. Hasil analisis KENLAYER untuk single axle load (roda gandar tunggal), respon yang dapat diidentifikasi dan dapat dianalisis hanya vertical compressive strain yang terdapat di permukaan tanah dasar dan horizontal tensile strain yang terletak di bawah aspal. Setelah itu dianalisis juga nilai repetisi ijin retak lelah serta nilai repetisi ijin retak deformasi. Grafik hubungan kadar bubutan baja dengan nilai regangan dapat dilihat pada Gambar 11 dan Gambar 12.

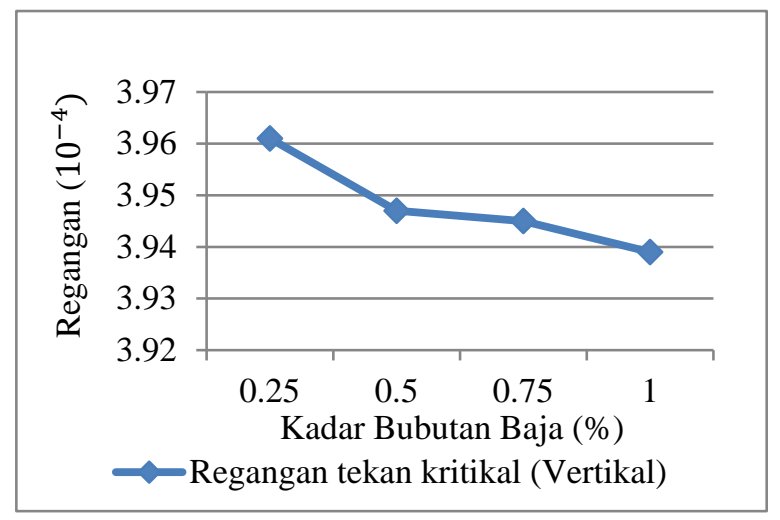

Gambar 11. Hubungan kadar bubutan baja dengan nilai regangan tekan kritikal

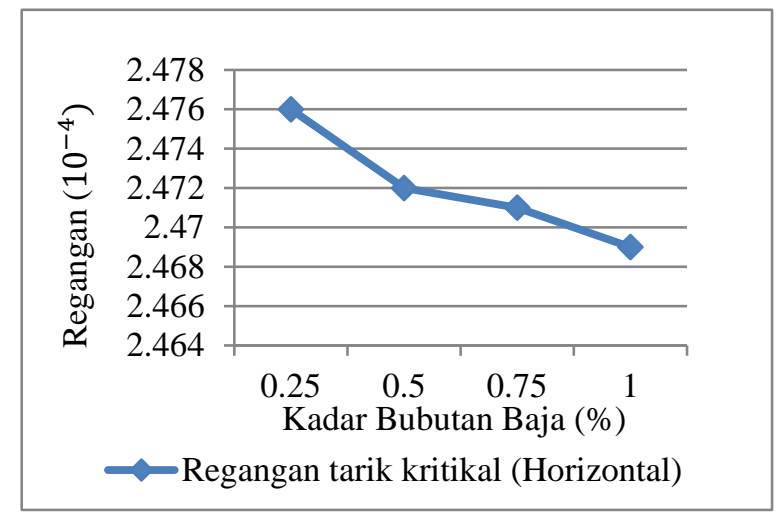

Gambar 12. Hubungan kadar bubutan baja dengan nilai regangan tarik kritikal

\section{Analisis pengaruh kadar bubutan baja terhadap regangan horizontal perkerasan}

Dari Gambar 11, tampak bahwa penambahan bubutan baja pada campuran mengakibatkan penurunan pada nilai regangan tekan kritikal pada campuran AC- WC.

\section{Analisis pengaruh kadar bubutan baja terhadap regangan horizontal perkerasan}

Dari Gambar 12, tampak bahwa penambahan bubutan baja pada campuran mengakibatkan penurunan pada nilai regangan tarik kritikal pada campuran AC- WC.

\section{KESIMPULAN DAN SARAN}

\section{Kesimpulan}

Kesimpulan yang didapatkan dari hasil penelitian yang telah dilakukan menggunakan benda uji campuran Asphalt Concrete - Wearing Course (AC-WC) dengan bahan tambah yaitu bubutan baja adalah

1. Penambahan kadar bubutan baja akan meningkatkan nilai dari VFWA dan mengakibatkan penurunan nilai dari VMA. nilai VFWA akan meningkat seiring dengan penambahan bubutan baja, sedangkan nilai VMA akan mengalami penurunan seiring dengan penambahan bubutan baja 
2. Nilai dari VITM akan mengalami penurunan seiring dengan penambahan kadar bubutan baja pada campuran. Nilai dari VITM pada kadar bubutan baja 1\% tidak memenuhi spesifikasi dan berada di bawah nilai minimum

3. Penambahan bubutan baja pada campuran akan meningkatkan nilai stabilitas dari campuran AC- WC

4. Nilai dari flow cenderung meningkat seiring dengan penambahan kadar bubutan baja pada campuran

5. Penambahan bubutan baja pada campuran akan cenderung meningkatkan nilai Marshall quotient dari campuran.

6. Berdasarkan hasil dari penelitian karakterstik Marshall campuran, didapat kadar bahan optimum yaitu sebesar 0,5625\% dari campuran menggunakan metode narrow range

7. Penambahan kadar bubutan baja pada campuran mengakibatkan penurunan pada nilai regangan tekan kritikal pada campuran AC- WC.

8. Penambahan kadar bubutan baja pada campuran mengakibatkan penurunan pada nilai regangan tarik kritikal pada campuran AC- WC.

\section{Saran}

Dari hasil penelitian yang telah dilakukan menggunakan benda uji campuran Asphalt Concrete - Wearing Course (AC-WC) dengan bahan tambah bubutan baja, terdapat beberapa saran untuk penelitian selanjutnya, yaitu:

1. Perlunya penelitian lebih lanjut dengan menggunakan penambahan kadar bubutan baja dan kadar aspal yang lebih banyak

2. Adanya pengujian ketahanan terhadap air dan porositas dari campuran

3. Dibutuhkan penelitian lebih lanjut karena range dari bubutan baja yang kurang signifikan. Diperlukan nilai bubutan baja yang lebih jauh agar dapat dilihat perbedaan dari hasilnya

4. Dibutuhkan penelitian lebih lanjut untuk variasi dari kadar aspal yang lebih baik dikarenakan nilai VITM pada kadar bubutan baja tertentu tidak memenuhi spesifikasi

\section{DAFTAR PUSTAKA}

Departemen Pekerjaan Umum. Spesifikasi Umum Bina Marga. Jakarta. 2018.

Clarkson H. Oglesby, Teknik Jalan Raya. Jilid 1. Edisi ke-4/ terjemahan Purwo Setianto, Jakarta, Erlangga, 1999.

Saodang, Hamirhan. Konstruksi Jalan Raya. Nova. Bandung. 2005.

Mamlouk, Michael S. The Handbook of Highway Engineering. Ed.T.W.Fwa. CRCpress ,2006.

Sukirman, Silvia. Perkerasan Lentur Jalan Raya. Nova. Bandung. 1999

Pramudya, Adhe, Ary Setiawan, Djoko Sarwono, Pengaruh penambahan limbah bubutan baja pada lapis tipis campuran aspal panas terhadap karakteristik kuat tarik tidak langsung, kuat tekan bebas dan permeabilitas, vol.1, no.4, Jakarta, 2013,pp. 519 - 526

Tora, Alpha, Ary Setiawan, Djoko Sarwono, Pengaruh penambahan limbah bubutan baja pada lapis tipis campuran aspal panas terhadap karakteristik Marshall. Vol.1, no.4, Jakarta. 2013, pp. 527-532 
Karakteristik Mekanis Campuran Laston Atas dengan

Nathanael, et al.

Penambahan Limbah Bubutan Baja 